\title{
Diferenciação por qualidade da carne bovina: a ótica do bem-estar animal
}

\author{
Differentiation for beef cattle quality: the view of the animal welfare
}

\section{Carolina Balbé de Oliveira ${ }^{{ }^{*}}$ Elísio Camargo De Bortoli ${ }^{\mathrm{I}}$ Júlio Otávio Jardim Barcellos ${ }^{\mathrm{II}}$}

\section{- REVISÃO BIBLIOGRÁFICA -}

\section{RESUMO}

Este estudo busca enfatizar como o bem-estar animal pode influenciar nos sistemas produtivos pecuários $e$ no produto final - a carne bovina. Surge da preocupação com as condições que os bovinos são manejados e chegam para abate nos frigoríficos, ocasionando prejuízos a todos os agentes da cadeia produtiva e da necessidade de obtenção de produtos seguros, com qualidade, e produzidos de forma sustentável e ambientalmente correta. Um bom manejo durante todo o sistema de criação se reflete na qualidade da carne. Ao se agregar qualidade, mesmo que por meio de características pouco identificáveis, promove-se a diferenciação do produto. Com certeza, assim como os prejuízos ocasionados pelo manejo inadequado, os ganhos da diferenciação, por meio de práticas de bem-estar animal, poderão ser compartilhados por todos os agentes da cadeia produtiva.

Palavras-chave: manejo, cadeia produtiva, bovinos de corte.

\section{ABSTRACT}

This paper aims to emphasize how the animal welfare can influence the cattle productive systems and in the final beef product. The study emerges from the preoccupation with the conditions that the cattle is handled and arrive for slaughter in the cold storage room. Impairing all the productive chain agentes, and the necessity to obtain safe products, with quality and produced in a sustainable and environmentally correct way. A good handling during all the breeding systems reflects in the meat quality. Aggregating quality, though by means of not very identifiable characteristics, the product diferenciation is promoted. For sure, as well as the impairment caused by the inadequate handling, the profits of diferenciation, by means of animal welfare practices, could be shared by all the agents of the productive chain.

Key words: handling, productive chain, cattle.

\section{INTRODUÇÃO}

Atualmente, divulga-se muito o bem-estar animal e a qualidade da carne bovina e vários estudos estão sendo realizados sobre o tema. Observa-se que não basta ter a melhor genética, a alta produtividade, a nutrição equilibrada e de boa qualidade, se o manejo com os animais está sendo incorreto.

Tais temas provavelmente surgem do crescente interesse dos consumidores pela qualidade e pela segurança dos produtos que consomem. Essa preocupação inclui também a não-exploração de mãode-obra, o menor uso de insumos externos e a maneira como o sistema produtivo é conduzido. Os consumidores modernos se interessam cada vez mais por produtos com um "histórico", que transmitem confiança e proporcionem maior satisfação, ou seja, demonstrem ética e estão interessados em saber como os animais foram criados, como foram alimentados e como foram abatidos. Quando se trata de produção animal, as práticas de bem-estar devem ser valorizadas, mesmo que, para agregar tais características, seja necessário desacelerar ou modificar os sistemas produtivos.

PARANHOS DACOSTA(2000) relatou que, nos últimos anos, o conceito bem-estar animal começou a ser implantado no cenário da produção animal, principalmente com a definição de protocolos de boas práticas de manejo. A princípio o propósito dessas ações era de cuidar do manejo com vistas a oferecer

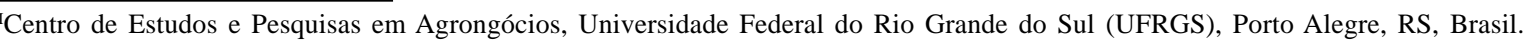
*Endereço para correspondência: Rua dos Andradas 1633, apt. 201, 97010-033, Santa Maria, RS, Brasil. E-mail: carolinabalbe@yahoo.com.br.

"Departamento de Zootecnia, UFRGS, Porto Alegre, RS, Brasil.
} 
produtos de qualidade e atender as exigências de mercados de exportação.

Para BROOM \& MOLENTO (2004), o bemestar animal é uma nova ciência, indispensável aos profissionais que trabalham em torno da interação entre humanos e animais e deve estar relacionado com conceitos como: necessidades, liberdades, felicidade, adaptação, controle, capacidade de previsão, sentimentos, sofrimento, dor, ansiedade, medo, tédio, estresse e saúde. Os autores acrescentaram que os efeitos sobre o bem-estar podem ser oriundos de situações como: doenças, traumatismos, fome, interações sociais, condições de alojamento, tratamento inadequado, manejo, transporte, mutilações variadas, tratamento veterinário, entre outras. Para GREGORY \& GRANDIN (1998), bem-estar animal refere-se ao sofrimento e à satisfação dos animais, mesmo que tais variáveis tenham difícil mensuração e suas causas e conseqüências sejam abordadas de diversas maneiras.

LLAVALLOL (2006) comentou que existem várias ferramentas que os produtores têm ao seu alcance para melhorar os índices de eficiência: manejo sanitário e preventivo contra várias enfermidades, como Febre Aftosa, BSE/Vaca Louca (Encefalopatia Espongiforme Bovina), enfermidades reprodutivas; controle do estado corporal das vacas de cria, alimentação adequada para terminação de gado de corte entre outras. Além disso, atualmente, vem se observando a importância das práticas de bem-estar animal, pois se os animais não estão sendo bem tratados, não expressarão seu máximo potencial produtivo.

Tais preocupações vêm para melhorar e aumentar a produção de carne bovina, para satisfazer a crescente demanda e para sair da atual conjuntura que atravessa o setor. Os cuidados vão muito além das questões ecológicas e têm uma incidência direta na rentabilidade e na qualidade da carne.

Este trabalho surge da preocupação com as condições que os bovinos são manejados e chegam para abate nos frigoríficos, ocasionando prejuízos a todos os agentes da cadeia produtiva e da necessidade de obtenção de produtos seguros, com qualidade e produzidos de forma sustentável e ambientalmente correta, utilizando práticas de bem-estar animal.

\section{DESENVOLVIMENTO}

Bem-estar animal na qualidade do produto

Por que se preocupar com o bem-estar animal? De imediato, porque é exigência dos clientes internacionais interessados na qualidade do produto final, assim como na qualidade dos processos de produção. Entre tais clientes, destaca-se a União
Européia - um dos principais agentes no reconhecimento das questões relacionadas ao bemestar animal. Nesse contexto, o bem-estar animal adquire cada vez maior relevância em todo o mundo e muitos países e consumidores impõem exigências legais. Para MOLENTO (2005), o mercado europeu possui uma declarada preferência por padrões elevados de bem-estar dos animais de produção.

No entanto, a todos os elos da cadeia da carne bovina (criadores, frigoríficos, atacadistas, transportadores, consumidores) é conveniente que sejam atendidas as práticas de bem-estar dos animais, pois os benefícios qualitativos e econômicos serão distribuídos a todos os integrantes da cadeia produtiva. Conforme MOLENTO (2005), as informações sobre as condições em que os animais de produção são mantidos percorrem toda a cadeia produtiva e se tornam atributos do produto final.

Muitos trabalhos demonstram que as práticas operativas e de manejo corretas asseguram um maior bem-estar do animal e obtêm melhores resultados econômicos, evitando ineficiência e perda de valor em toda a cadeia da bovinocultura de corte e produzindo um produto que não deixa de ser uma commodity, mas que apresenta diferenciação por sua qualidade melhorada.

Segundo NEVES et al. (2005), com a maior competição nos mercados e o cenário de oferta superior à demanda, cada vez mais as empresas lutam para melhorar sua posição relativa de mercado e diferenciar sua oferta de seus concorrentes.

A vantagem competitiva ocorre quando uma empresa apresenta um desempenho acima da média a longo prazo e isso se dá por baixo custo e diferenciação (ANDREOTTI et al., 2002).

Para PORTER (1991), a diferenciação, quando alcançada, é uma estratégia para obtenção de rendimentos acima da média, pois a identificação e o reconhecimento de um produto cria um sentimento de lealdade nos clientes, bem como proporciona menor sensibilidade ao preço dos produtos.

CARNEIRO et al. (1997), corroborando as idéias de PORTER (1991), afirmaram que a estratégia de diferenciação pressupõe que a empresa ofereça, no âmbito de toda a indústria, um produto ou serviço que seja considerado único pelos clientes. Nesse caso, o uso da prática de bons tratos com os animais irá produzirá como produto final algo diferenciado dos demais, ou seja, uma carne de qualidade.

Em relação a esse assunto,pode-se abordar uma estratégia genérica apresentada por CARNEIRO et al. (1997), referindo-se à estratégia de diferenciação por qualidade. Conforme esses autores, esta estratégia 
se caracteriza por oferecer (com o mesmo preço ou um preço diferenciado devido à qualidade) um produto que, embora não fundamentalmente diferente, é melhor que os concorrentes.

A estratégia de diferenciação por qualidade está relacionada com características do produto que o faz melhor - não fundamentalmente diferente, somente melhor (NEVES et al., 2005). Corroborando estas idéias, AZEVEDO (2005) afirmou que a distinção entre produtos surge da percepção dos consumidores sobre tal diferença, sendo fundamentais os conceitos de qualidade percebida. Para o autor, um produto diferenciado não precisa ser fisicamente distinto. Esse mesmo autor também enxerga a diferenciação como uma estratégia de marketing, em que se buscam elementos que distingam o produto de uma empresa das demais concorrentes e a diferenciação se dá por comparação com os produtos das demais empresas. No caso abordado, a diferenciação ocorre pela presença ou não de práticas de bem-estar animal nos sistemas produtivos.

Para KOTLER (1996), a diferenciação é vista em quatro dimensões básicas: produto, serviço, pessoal e imagem. A diferenciação de produto envolve características de desempenho, conformidade, durabilidade, confiabilidade, facilidade de conserto e uso. A diferenciação de serviços envolve entrega, instalação, treinamentos, consultoria e conserto. Já os diferenciadores de pessoal são competência, cortesia, credibilidade, confiabilidade, responsabilidade e comunicação. Por fim, a diferenciação pela imagem envolve a maneira que os consumidores reagirão diante de produtos aparentemente iguais, porém, de marca ou origem diferentes.

A forte concorrência em nível de mercados mundiais compradores de carne leva os países produtores a um novo conceito de produção e benefício: um mercado que a diferença é dada pela “qualidade do produto”. Portanto, uma carne produzida com animais bem tratados desde o nascimento no estabelecimento do produtor até o momento de sua chegada no frigorífico terá, sem dúvida, melhor aspecto, textura e sabor que aquela que foi manejada em piores condições.

ZAPIOLA (2006) comentou que uma informação norte-americana de três auditorias nacionais (1991, 1995 e 2000) estimaram perdas em U\$47,00, U\$28,00 e U\$40,00, respectivamente, por cada animal abatido, somente por falhas de manejo. Estes valores representam entre 4\% e 6\% do valor do animal vivo. Este relatou, também, em outro estudo no Uruguai, em 2002, que as perdas por mau manejo somaram quase U\$16,00 por cabeça, o que representava $7 \%$ do valor do animal.
GRANDIN (2006), referindo-se a seu trabalho de mais de três décadas na estruturação e na adequação de plantas frigoríficas e no treinamento de funcionários nos Estados Unidos, visando à melhoria dos padrões de bem-estar no abate de bovinos e suínos, afirmou que as auditorias realizadas pelas grandes corporações compradoras de carne são o caminho mais efetivo para que ocorram melhorias de bem-estar no abate dos animais. Tais corporações utilizam sua força comercial para obter os resultados esperados. Isso revela a importância da percepção dos mercados consumidores em relação às práticas de bem-estar animal e a interação desta com a qualidade do produto final.

Adicionalmente, é cada vez maior a preocupação com certificação por parte dos consumidores de carne dos países compradores dos nossos produtos. Esta certificação engloba todas as etapas do processo produtivo (do campo até o consumidor final), incluindo o cumprimento de normas de bem-estar, sanidade e origem dos produtos.

\section{Manejo e práticas de bem-estar animal}

De acordo com GREGORY \& GRANDIN (1998), os humanos têm responsabilidade pelo sofrimento dos animais nas seguintes situações: ignorância - a pessoa não conhece aquilo que faz; inexperiência - conhece aquilo que faz, mas não sabe como fazê-lo; incompetência - falta de habilidade para desempenhar as tarefas e falta de consideração ou zelo pelos animais.

Para BROOM \& MOLENTO (2004), as pessoas que trabalham com animais devem reconhecer as evoluções que alteraram as relações entre seres humanos e animais; manterem-se informadas sobre as explicações que a ciência vem propondo para determinadas respostas dos animais a determinadas situações ou problemas; e refinarem as formas de se medir o grau de bem-estar dos animais para que tais avaliações sejam úteis no melhoramento das relações entre seres humanos e animais.

Segundo CRUZ \& SOUSA (2005), a correta planificação de instalações pecuárias, tanto em nível espacial quanto em nível do condicionamento ambiental, é fundamental para que sejam cumpridas regras básicas de bem-estar animal. Estas regras baseiam-se, resumidamente, na ausência de condições de estresse, definido pelos autores como uma resposta biológica desencadeada quando um indivíduo recebe uma ameaça às suas condições normais, desencadeando um estado de alerta que, quando prolongado, pode conduzir à exaustão.

SOUSA (2005) acrescentou que o sofrimento normalmente está relacionado com o bem-estar dos 
animais, sendo o estresse o principal mecanismo de medida do bem-estar animal, mas a falta de bem-estar não é, necessariamente, sinônimo de sofrimento. Para a autora, é difícil mensurar o grau de satisfação dos animais com seu ambiente. A manifestação de sinais de dor, angústia, medo, frustração, raiva e outras emoções são indicativos de desconforto e sofrimento. Porém, o conforto mental pode não estar relacionado às condições físicas, pois o animal pode estar saudável e bem nutrido, mas sofrendo mentalmente.

O que são maus tratos?

É possível caracterizar como maus tratos o manejo dos animais pela força que trabalha contra o animal para obrigá-lo, mediante distintas formas de violência, a fazer o que se deseja: entrar na mangueira (curral), subir no caminhão, entrar no brete, etc.

Golpes com paus, guizos, picana elétrica (choque), uso de cães, seringas cheias, mangueiras em mal estado de conservação e manejo com muita rapidez são alguns exemplos de maus tratos feitos durante o manejo dos animais.

Geralmente, o mau trato dos animais se origina do desconhecimento do comportamento dos bovinos. As pessoas que trabalham com estes animais deveriam primeiramente conhecer como o bovino vive para, assim, fazer uso deste conhecimento e manejálos corretamente.

PETHERICK (2005), ao estudar questões relacionadas ao bem-estar, em sistemas extensivos de criação de bovinos no Norte da Austrália, apontou como medidas para melhorá-lo: a adoção de suplementação e melhorias no planejamento alimentar em períodos secos, o uso mais apropriado dos programas de vacinação, a utilização de raças (genótipos) adequadas às condições climáticas locais, o desenvolvimento de técnicas menos invasivas de castração e a necessidade de mudanças na legislação em relação à identificação (marcação) dos animais.

ZAPIOLA (2006) comentou que não há uma receita para o manejo dos animais, mas ele faz algumas considerações relevantes: (1) eliminar as condutas agressivas: estas compreendem os gritos, as agressões físicas, o uso de cães agressivos e procurando sempre trabalhar em silêncio; (2) jamais trabalhar apurado; (3) não movimentar mais animais do que o necessário; (4) mover os animais nem muito folgados nem muito apertados e separar os animais em lotes de categorias; (5) não mesclar lotes na hora de trabalhá-los na mangueira; (6) durante a descorna, separar animais aspados dos mochos para evitar lesões; (7) desmamar em duas etapas: não separar por completo no primeiro momento a vaca do terneiro; (8) não fazer os animais esperarem mais do que o necessário e nem encerrá-los por nada: a mangueira é somente um local de passagem e não para os animais ficarem encerrados durante horas; (9) nunca manejar o bovino isoladamente; (10) habituar o gado à presença humana; (11) trabalhar a pé na mangueira; (12) selecionar e capacitar os peões: são estas pessoas que trabalham diretamente com o patrimônio dos produtores; (13) revisar, manter e melhorar as instalações; (14) cuidar e eleger os motoristas para o transporte do gado e carregar o caminhão boiadeiro com o número adequado de animais para o seu espaço; (15) monitorar o frigorífico: o produtor deve acompanhar o abate dos seus animais; (16) não se descuidar do bem-estar dos animais, pois esta prática não é só mais um requisito para cumprir por obrigação externa e, sim, uma prática integral e permanente do gerenciamento moderno.

\section{CONCLUSÃO}

Com este estudo, percebe-se o despertar de alguns elos da cadeia da bovinocultura de corte para as práticas de bem-estar animal, ou seja, as preocupações com o mau manejo dos animais estão ganhando adeptos e não mais sendo vistas apenas como exigências de comercialização. $\mathrm{O}$ mau manejo, às vezes, passa desapercebido, ocasionando perdas de eficiência do sistema produtivo, que, em muitos casos, são atribuídas à deficiências na alimentação, a enfermidades, etc.

O aperfeiçoamento das práticas de manejo pode tornar os sistemas produtivos mais competitivos, pois, além de evitar perdas, é possível incrementar a produção com o melhoramento e a adequação no manejo dos animais. Isso sem mencionar um produto final diferenciado, uma carne bovina de qualidade, com atributos que atualmente são valorizados pelos principais mercados internacionais, como a União Européia.

Com certeza, assim como os prejuízos ocasionados pelo manejo inadequado e pela ausência ou pela pouca expressividade das práticas de bem-estar animal nos sistemas produtivos pecuários, os ganhos da diferenciação, que tais ações podem proporcionar, poderão ser compartilhados por todos os agentes da cadeia produtiva.

\section{REFERÊNCIAS}

ANDREOTTI, E.G. et al. Vantagem competitiva segundo Michael Porter. In: SEMINÁRIO USP DE CONTABILIDADE, 2., 2002, São Paulo. Capturado em 21 ago. 2006. Online. Disponível em: http://www.eac.fea.usp.br/congressousp/ seminario2/trabalhos/B53. 
AZEVEDO, P.F. Concorrência no agribusiness. In: ZYLBERSZTAJN, D.; NEVES, M.F. Economia e gestão dos negócios agroalimentares. São Paulo: Pioneira Thomson Learning, 2005.

BROOM, D.M.; MOLENTO, C.F.M. Bem-estar animal: conceito e questões relacionadas - Revisão. Archives of Veterinary Science v.9, n.2, p.1-11, 2004.

CARNEIRO, J.M.T. et al. Porter revisitado: análise crítica da tipologia estratégica do mestre. In: ENANPAD, 21., 1997, Rio de Janeiro. Anais... Rio de Janeiro, 1997.

CRUZ, V.F.; SOUSA, P. Sistema integrado de monitoramento do bem-estar animal. EMBRAPA Suínos e Aves. Artigos. 2005.

GRANDIN, T. Progress and challenges in animal handling and slaughter in the U.S. Fort Collins, USA: Applied Animal Behaviour Science, 2006. p.129-139.

GREGORY, N.G.; GRANDIN, T. Animal welfare and meat science. London, UK: Cabi, 1998.

KOTLER, P. Marketing: edição compacta. São Paulo: Atlas, 1996.

LLAVALLOL, A. La importância del bienestar animal. In: Bienestar animal y calidad de la carne. Argentina: Instituto de Promoción de la Carne Vacuna Argentina - IPCVA, 2006. (Cuadernillo Técnico).
MOLENTO, C.F.M. Bem-estar e produção animal: aspectos econômicos - Revisão. Archives of Veterinary Science v.10, n.1, p.1-11, 2005.

NEVES, M.F. et al. Processo estratégico de marketing e plano de marketing para o agronegócio. In: SEMEAD, 7., 2005. Anais.... Capturado em 21 ago. 2006. On line. Disponível em: http://www.ead.fea.usp.br/ Semead/7semead/paginas/ a r t i g o s \% $20 \mathrm{rec}$ e bi d o s / A g r o n e g o c i o s / AGRO19Processoestrat\%E9gicodemktparaoag.PDF.

PARANHOS DA COSTA, M.J.R. Ambiência na produção de bovinos de corte. In: ENCONTRO ANUAL DE ETOLOGIA, 18., 2000. Florianópolis. Anais.... Sociedade Brasileira de Etologia, 2000. p.1-15.

PETHERICK, J.C. Animal welfare issues associated with extensive livestock production: The northern Australian beef cattle industry. Applied Animal Behaviour Science, Rockhampton, p.211-234, 2005.

PORTER, M.E. Estratégia competitiva - Técnicas para análise de indústrias e da concorrência. 7.ed. Rio de Janeiro: Campus, 1991.

SOUSA, P. Exigências atuais de bem-estar animal e a sua relação com a qualidade da carne. EMBRAPA Suínos e Aves. Artigos. 2005.

ZAPIOLA, M.G. El bienestar animal y la calidad de la carne. In: Bienestar animal y calidad de la carne. Argentina: Instituto de Promoción de la Carne Vacuna Argentina - IPCVA, 2006. (Cuadernillo Técnico). 